\title{
REASONS AND STRATEGIES ASSOCIATED WITH POSITIVE INTERACTION BETWEEN WORK AND HOME AMONGST MANAGERS: AN EXPLORATORY STUDY
}

\section{Authors:}

Janet Oosthuizen

Karina Mostert ${ }^{1}$

\section{Affiliations:}

${ }^{1}$ WorkWell: Research

Unit for Economic and

Management Sciences,

North-West University,

Potchefstroom Campus,

South Africa

\section{Correspondence to:}

Karina Mostert

email:

Karina.Mostert@nwu.ac.za

\section{Postal address:}

WorkWell: Research

Unit for Economic and

Management Sciences,

North-West University,

Private Bag X6001 (Internal

box 202), Potchefstroom

2520, South Africa

\section{Keywords:}

positive interaction

between work and home

reasons; strategies;

managerial employees;

exploratory qualitative interviews

Dates:

Received: 24 Nov. 2009

Accepted: 28 July 2010

Published: 16 Nov. 2010

How to cite this article: Oosthuizen, J., \& Mostert, K. (2010). Reasons and strategies associated with positive interaction between work and home among managers: An exploratory study. $S A$ Journal of Industrial Psychology/SA Tydskrif vir Bedryfsielkunde, 36(1), Art \#877, 13 pages. DOI: 10.1402/ sajip.v36i1.877

This article is available at: http://www.sajip.co.za

Note:

The material described in this article is based upon work supported by the National Research Foundation under reference number TTK2006061200018. This article was part of the first author's master's thesis.

(C) 2010. The Authors. Licensee: OpenJournals Publishing. This work is licensed under the Creative Commons

Attribution License.

\section{ABSTRACT}

Orientation: In order to facilitate positive interaction between work and home, it is necessary to understand the reasons for and strategies used by managerial employees to manage this interaction.

Research purpose: The objectives of this study were to determine, (1) reasons why employees experience high or low positive work-home interaction and (2) strategies that employees with high and low positive interaction use.

Motivation for the study: Positive interaction between work and home, particularly in managerial employees, is becoming increasingly more important with a view to ensuring a stable and healthy work-home life.

Research design, approach and method: A random clustered sample $(n=275)$ was taken from managerial employees in a multinational organisation and the Survey Work-Home InteractionNijmegen (SWING) was administered to identify participants with high and low positive interaction between work and home respectively. Thereafter, exploratory qualitative interviews were conducted with selected participants $(n=32)$ to deduce themes for the above-mentioned objectives. Content analysis was used to analyse, quantify and interpret the research data.

Main findings: Reasons for high or low positive interaction were identified in conjunction with previous research. Ten successful strategies for positive interaction between work and home were identified and reported.

Managerial/practical implications: Organisational recommendations made include changing the organisational culture to being more supportive, developing employees for future positions and creating social networks. In addition, individual strategies and recommendations for future research are identified.

Contribution/value-add: This study contributes to the limited research on strategies for positive interaction between work and home among managerial employees.

\section{INTRODUCTION}

According to Jones, Burke and Westman (2006), the study of work-life balance and integration has become increasingly relevant for several reasons. These reasons include demographic and social changes, women (and especially working mothers) entering the workforce, technological advancement and globalisation that are changing the way people work and play and, lastly, job insecurity due to constant change together with expectations of increased performance. Under these working conditions, the boundary between work and personal life is becoming unclear, and the integration of work and personal life is therefore becoming an important and challenging issue to many individuals (Duxbury, 2004; Jones et al., 2006). In addition, evidence suggests that the demands of work and the concomitant lack of work-home integration and balance have a negative effect on both individuals and organisations. According to Stoner, Robins and Russell-Chapin (2005), imbalance or lack of effective integration can result in several negative physiological responses such as insomnia, overeating and poor nutrition. They also found that individuals may stop exercising or feel tired and worn out because of this imbalance. Frone, Russell and Cooper (1997) found that work-home conflict leads to depression, physical health complaints and hypertension. Work-home interference was also found to be related to burnout and illhealth in the South African environment (Koekemoer \& Mostert, 2006; Oldfield \& Mostert, 2007; Mostert, 2009; Mostert, Peeters \& Rost, in press). Duxbury and Higgins (2003) further found that individuals experience stress and burnout while the effects of these on organisations translate into absenteeism, high turnover rates and lower performance. It is therefore important for organisations to recognise and manage these instances by providing support programmes aimed at the positive integration of work and personal life.

Work-family conflict, work-family integration, work-life interaction and work-life balance have been studied extensively for a number of years (for a review, see Byron, 2005; Eby, Casper, Lockwood, Bordeaux \& Brinley, 2005; Geurts \& Dikkers, 2002). According to a meta-analysis by Eby et al. (2005), studies on work-family conflict set out with a fairly one-dimensional conceptualisation of the construct. Thereafter, the focus shifted to the multidirectional interaction between the two domains. Recently, more complex relationships of work-family conflict are being studied. There is currently also a tendency towards the use of the term 'work-home interaction' instead of 'work-home balance', as balance implies a 50:50 weight ratio - which may not always be the desired situation (Koekemoer \& Mostert, 2010; Lewis, Rapoport \& Gambles, 2003). In addition, Seligman and Csikszentmihalyi (2000) introduced the positive psychology paradigm at the turn of the 20th century, focusing on how to obtain psychological health and wellness instead of emphasising dysfunction and illness. This shift had a fundamental influence 
on studies on work-life interaction and moved the focus of these studies towards positive facilitation and enrichment. Several studies have been conducted with a view to determine the relationships between home and work characteristics and positive interaction between work and home (Bakker \& Geurts, 2004; Greenhaus \& Powell, 2006; Koekemoer \& Mostert, 2010) as well as recovery, engagement, leisure and wellbeing (Hammer, Cullen, Neal, Sinclain \& Shafiro, 2005; Haworth \& Lewis, 2005; Sonnentag, 2003)

Work-home interaction is a process in which an individual's functioning and behaviour in one domain (e.g. home) is influenced (negatively or positively) by load reactions that have built up in the other domain (e.g. work) (Geurts et al., 2005). More specifically, positive work-home interference (PWHI) can be defined as the positive influences developed at work that facilitate functioning at home. Positive home-work interference (PHWI) can be defined as those positive influences developed at home that facilitate functioning at work (Geurts et al., 2005).

The concept of positive work-home interaction as well as the predictors and consequences thereof have been studied by international and South African researchers (i.e. Greenhaus \& Powell, 2006; Grzywacz \& Butler, 2005; Hakanen, Peeters \& Perhoniemi, submitted; Montgomery, Peeters, Schaufeli \& Van Ouden, 2003; Mostert, 2006; Mostert, Cronjé \& Pienaar, 2006; Mostert et al., in press). However, the issue of how individuals cope with their life situation remains relatively unexplored (Heraty, Morley \& Cleveland, 2008). Duxbury (2004) stresses the importance of using strategies aimed at facilitating positive interaction between work and home and emphasises that strategies have to be incorporated by individuals themselves as well as by the organisation. Some of the successful strategies studied in the literature focus typically on coping with the effects of negative interaction. Such strategies include putting the situation in perspective, using emotion-focused coping and turning to religion (Beehr, Johnson, Nieva \& Hurrell, 1995), using cognitive appraisal, self-controlling, seeking social support, planful problem solving and positive reappraisal (Brink \& De la Rey, 2001), using social support networks (Carlson \& Perrewe, 1999), organising time, working actively at balancing one's life, goal setting, focusing on the positive, remaining healthy and turning to social support (Duxbury, 2004), making use of organisational support and using individual strengths to cope (Brough, O'Driscoll, \& Kalliath, 2005; Kirchmeyer \& Cohen, 1999), active coping (Beutell \& Greenhaus, 1983) and, lastly, structural role redefinition, personal role redefinition and reactive role behaviour (Lo \& Stone, in press). Unsuccessful strategies used include problemfocused coping and assertiveness (Beehr et al., 1995), accepting responsibility, distancing and escaping avoidance (Brink \& De la Rey, 2001) and reactive coping (Beutell \& Greenhaus, 1983).

The lack of research on strategies aimed at positive interaction between work and home domains (specifically in the South African context) suggests the relevancy of an exploratory study in this regard. The objectives of this study were therefore to, (1) determine reasons why employees experience high or low positive work-home interaction and (2) determine those strategies that are used by employees with high and low positive interaction.

The study was conducted in a multinational, fast-moving consumable goods organisation that realised the importance of research on effective strategies for positive interaction between work and home. This organisation currently experience high employee turnover in managerial positions, specifically due to perceived work-life balance problems caused by the nature of managerial work. The organisation encourages managerial employees to be accountable, hardworking and loyal, and also expect employees to set and reach higher targets every year. These organisational values sometimes create an environment where work-life balance and positive interaction between work and private life seem almost impossible to achieve. The organisational effectiveness study conducted by the organisation in March 2009 showed that employees experience low levels of work-life satisfaction - especially those in senior managerial positions, of which only $58 \%$ reported satisfaction with the status of their work-life balance. It is evident that a study on positive interaction between work and home among managerial employees can contribute significantly to the organisation being researched as well as to the field of research. The specific challenges faced by managerial employees in this organisation made this organisation an appropriate site for studying work-life interaction.

\section{RESEARCH DESIGN}

A mixed-method research design was used, according to which the study was divided into two phases. During the first phase, questionnaires were distributed in order to establish an objective identification of certain individuals who experience very high and/or very low positive interaction. Thereafter, exploratory interviews were conducted in order to determine reasons for experiencing (high/low) positive interaction and strategies aimed at managing the interaction between work and home. The research design of the first phase is discussed briefly, while a detailed description is given of the research design of the second phase. This study is located in the post-positivism paradigm within the broad field of qualitative research (Guba \& Lincoln, 1994). The methodology used in this paradigm aims at enquiring information in more natural settings, collecting more situational information and determining the meanings and purposes that individuals ascribe to their actions.

\section{PHASE 1: QUESTIONNAIRE SURVEY}

\section{Research approach}

A descriptive quantitative phase entailed that data were gathered through questionnaires distributed by means of crosssectional sampling (Shaughnessy, Zechmeister \& Zechmeister, 2003).

\section{Research method}

The research method is discussed with reference to sampling, data-collection methods and data analyses.

\section{Sampling}

A random clustered sample $(N=570)$ was taken from employees in all managerial positions in a national organisation in the fastmoving consumable goods sector. A total of 275 questionnaires were completed without any missing values, which resulted in a $48 \%$ response rate. The procedure used to sample the participants began with the random cluster sampling of the 12 districts in the organisation by using the random number generator method (Rice, 1995). A total of six random numbers were generated to serve as index numbers for districts chosen from the list in order to sample the appropriate number of participants. Cluster-size differentiation was controlled in order to minimise the drawback of unequal clusters (Rice, 1995). Thereafter, the questionnaire was electronically distributed to all managerial employees in each identified cluster.

The quantitative sample consisted of $61.8 \%$ male and $38.2 \%$ female participants. The race ratio of the sample closely matched the ratio of the organisation, with the majority of the sample being White (57.8\%) and the remaining $42.2 \%$ comprising of African (22.2\%), Indian (15.3\%) and Coloured (4\%) participants. Most of the participants were English speaking $(61.1 \%)$, closely followed by Afrikaans participants $(24.70 \%)$. Only $14.2 \%$ of the participants spoke other official languages. A total of $8.40 \%$ of the participants hold a Grade 12 qualification, while $35.30 \%$ have a diploma, $27.60 \%$ have a degree and $28.70 \%$ 
have a postgraduate qualification. More than half $(n=165)$ of the participants are married, while the remainder of the participants are divided between being single $(n=69)$, living with a partner $(n=28)$ and other unspecified circumstances $(n$ $=13$ ). At the time of the research, the ages of the participants ranged from 20 to 62 , with the age group $30-39$ being the most prevalent $(45.5 \%)$.

\section{Data-collection methods}

Two scales of the Survey Work-Home Interaction Nijmegen (SWING) (Geurts et al., 2005) were used to measure positive interaction between work and home. PWHI was measured by five items (e.g. 'How often does it happen that you manage your time at home more efficiently as a result of the things you have learned on your job?'). PHWI was also measured using five items (e.g. 'You have greater self-confidence at work because you have your home life well organised'). All items were scored using a four-point frequency rating scale ranging from 0 (never) to 3 (always). Geurts et. al. (2005) found the two scales to be reliable $-\alpha=0.75$ for PWHI and $\alpha=0.81$ for PHWI. Pieterse and Mostert (2005) also noted reliability coefficients of $\alpha=0.79$ (PWHI) and $\alpha=0.76$ (PHWI) in their psychometric analysis of the SWING in the South African environment.

\section{Data analyses}

The statistical analysis was conducted using the SPSS program (SPSS, 2005) in order to divide participants into two groups, (1) high positive interaction between work and home and (2) low positive interaction between work and home. Firstly, Cronbach's alpha coefficients were calculated for the PWHI and PHWI constructs to determine their internal consistency. The reliability of both the PWHI $(\alpha=0.76)$ and the PHWI $(\alpha=$ $0.75)$ constructs were confirmed. Total scores for PWHI and PHWI were determined per participant by adding together the totals of the individual items that constituted these constructs. The amalgamation of the two constructs was administered by calculating a construct called 'positive interaction' (Positive interaction $=\mathrm{PWHI}+\mathrm{PHWI})$.

In order to establish the high and low groups, participants were classified from high to low according to their scores on the positive interaction construct. The means were determined for the positive interaction construct $(\mu=16.7)$ in order to determine a desirable cut-off point for grouping. All participants with scores higher than the mean were grouped into the high positive interaction group $(n=139)$, while participants with scores lower than the mean were grouped into the low positive interaction group $(n=136)$. Consequently, the 20 participants with the lowest and highest scores were selected for interviewing.

\section{PHASE 2: EXPLORATORY INTERVIEWS}

\section{Research approach}

In this study, a qualitative research design with an exploratory approach was used to explore and describe participants' reasons for and strategies associated with high and low positive interaction between work and home. With qualitative studies, researchers attempt to understand the world from the participants' point of view and unfold the meaning of people's experiences to their lived world prior to any scientific explanations (Kvale, 1996). The ontological theories that this study draws from are based on the assumption that we all have a work and home life that are separate domains in our lives, that interaction between these two domains takes place, and that this interaction can be positive or negative. Epistemologically speaking, the current study focused on gaining knowledge about the social reality (as defined by the ontological assumptions) by asking fundamental questions regarding how participants experience the interaction between work and home, and how they manage this interaction. According to Lincoln and Guba (2003), the methodology used in a qualitative study refers to the general principles underlying how we investigate a social phenomenon in a certain social and cultural context and also how we can acquire that knowledge. Qualitative studies are based on meanings expressed through words and other symbols or metaphors, and the designs most often used include case study research, participant observation, unstructured in-depth interviews, focus groups and participatory research (Welman, Kruger \& Mitchell, 2005). The exploration of ways in which individuals successfully manage the interface between work and home was conducted by means of an exploratory approach, in-depth interviews with selected participants and content analysis. A qualitative approach was especially beneficial to this study, since participants were allowed to describe what is meaningful or important to them in their own words rather than being restricted to predetermined categories regarding work-personal life interaction.

\section{Research strategy}

The research strategy includes the investigation of multiple cases within a uniform setting to reach the research objectives of this study. Data were gathered from multiple selected research subjects in an organisation in the fast-moving consumable goods industry. This selection was done to include managerial employees with specific levels of positive interaction between work and home domains and had the specific research questions and setting in mind. The rationale for the selection is explained in the research method.

\section{Research method}

The research method is discussed with reference to research setting, entrée and establishing researcher roles, sampling, data collection methods, recording of the data, data analyses, strategies employed to ensure data quality and reporting.

\section{Research setting}

The research setting was an important consideration prior to data collection. The research field had to be determined and permission had to be obtained to enter the field. According to De Vos, Strydom, Fouché and Delport (2005), the specific field in which the inquiry is to be undertaken is directly linked to the choice of the problem. The research objective in this study determined the research field: management employees in a beverage-manufacturing and distribution company in the fastmoving consumable goods industry.

\section{Entrée and establishing researcher roles}

Permission to conduct this research was obtained from the organisation by means of a letter to the group's human resource manager, which explained the significance of the study for the individuals as well as the organisation. The main researcher is a permanent employee in the organisation and holds the position of Organisational Development Specialist. This role involves communication, change management and training and development of employees during organisational change and transformation. According to De Vos et al. (2005), the maintenance of good relationships with the participants is important in a qualitative study and can influence the accuracy and reliability of the information gathered. The fact that the researcher who conducted the interviews is an employee of the organisation generally set the participants at ease to share information. However, it was clarified upfront that the interviews were not initiated by the organisation itself, but is done by an educational institution in collaboration with the organisation. This facilitated honest and open communication and contributed to the creation of a non-threatening environment.

\section{Sampling}

The 40 participants identified in the quantitative phase were contacted and interviews were scheduled with them. Data 
TABLE 1

Characteristics of participants

\begin{tabular}{|c|c|c|c|c|c|}
\hline \multirow[b]{2}{*}{ Item } & \multirow[b]{2}{*}{ Category } & \multicolumn{2}{|c|}{ Postive Interaction (Frequency) } & \multicolumn{2}{|c|}{ Total } \\
\hline & & High & Low & Frequency & $\%$ \\
\hline \multirow[t]{2}{*}{ Gender } & Male & 11 & 8 & 19 & $59 \%$ \\
\hline & Female & 6 & 7 & 13 & $41 \%$ \\
\hline \multirow[t]{5}{*}{ Race } & White & 5 & 11 & 16 & $50 \%$ \\
\hline & African & 8 & 1 & 9 & $28 \%$ \\
\hline & Coloured & 0 & 2 & 2 & $6 \%$ \\
\hline & Indian & 4 & 1 & 5 & $16 \%$ \\
\hline & Other & 0 & 0 & 0 & $0 \%$ \\
\hline \multirow[t]{4}{*}{ Education level } & Grade 12 & 3 & 2 & 5 & $16 \%$ \\
\hline & Diploma & 8 & 5 & 13 & $41 \%$ \\
\hline & Degree & 2 & 5 & 7 & $22 \%$ \\
\hline & Postgraduate degree & 4 & 3 & 7 & $22 \%$ \\
\hline \multirow[t]{4}{*}{ Marital status } & Single & 6 & 2 & 8 & $25 \%$ \\
\hline & Married & 11 & 10 & 21 & $66 \%$ \\
\hline & Living with partner & 0 & 2 & 2 & $6 \%$ \\
\hline & Other & 0 & 1 & 1 & $3 \%$ \\
\hline \multirow[t]{4}{*}{ Age } & $20-29$ & 4 & 2 & 6 & $19 \%$ \\
\hline & $30-39$ & 7 & 5 & 12 & $38 \%$ \\
\hline & $40-49$ & 4 & 4 & 8 & $25 \%$ \\
\hline & $50+$ & 2 & 2 & 4 & $13 \%$ \\
\hline
\end{tabular}

saturation was reached (Woods \& Catanzaro, 1988) after the 25th interview, but seven more interviews were conducted to ensure reliability and integrity of the data $(n=32)$. The characteristics of participants in both groups are provided in Table 1.

Table 1 indicates that there were slightly more male (59\%) than female $(41 \%)$ participants. The sample consisted of participants from various races, including $50 \%$ white and $50 \%$ equity as per the organisation's Broad-Based Black Economic Empowerment targets. Most of the participants have a diploma (44\%). The rest of the participants have a Grade $12(16 \%)$ qualification, a degree $(22 \%)$ or a postgraduate qualification $(22 \%)$. The majority of the participants were married $(66 \%)$. Participants between 30 and 39 years constituted $38 \%$ of the sample, while $25 \%$ were between the ages of 40 and 49 , and $19 \%$ were between 20 and 29 years of age. Only $13 \%$ were older than 50 years.

\section{Data collection methods}

The 32 managerial employees were interviewed using a semi-structured, open-ended questionnaire format. The interviews were held in the employees' own offices, except when requested otherwise. The interviewer paid attention to the atmosphere in the room, limited interruptions and kept the participants at ease and relaxed at all times. Interviews were conducted in the preferred language of the participant (either English or Afrikaans). The interviewer introduced herself, explained the rationale behind the study and gave general interview instructions. The interviewer mentioned that the interview would be recorded on a videotape, explained the reasons for this and obtained informed consent from the participants. It was also mentioned to the participants that their identity would be protected and that all data will be treated confidentially. The main researcher (the first author) was respectful of all participants irrespective of race, age, gender and political or religious outlook, and focused specifically on treating all participants with respect and dignity. The main researcher also attempted to ensure the psychological welfare of the participants and made it clear that they could withdraw from the study at any time, and also that they were not obliged to answer any questions with which they might feel uncomfortable.

The interviews were informal, comfortable, honest and open. The interviewer initiated the interviews by explaining the rationale, defining the notion of work-home interaction and mentioning the group in which the participants were categorised. The interviews were constructed around the following two questions:

- Why do you think you experience this high/low interaction between your work and home life?

- What strategies do you use to manage the interaction between work and home life?

The answers were further explored by following up and/ or clarifying questions in order to obtain further detail from the participants. Non-directive dialogue techniques such as minimal verbal responses (e.g. 'mm-mm, yes, I see'), paraphrasing (stating the participant's words in another form with the same meaning), clarification (e.g. 'Can you tell me more about ...' and 'You seem to be saying ...'), reflection (e.g. 'So, you believe that ...'), reflective summary ('So what you're saying ...') and silences were used to assist the participants to share their experiences. In addition to verbal information that was obtained during the interviews, the main researcher also took down field notes that observed behaviours of participants throughout the interviews. These field notes included the manner in which the participants acted or reacted when answering the questions as well as their behaviour during the interview (e.g. being distant when asked questions and long pauses in the conversation). According to De Vos et al. (2005), field notes contain a comprehensive account of participants, events taking place, actual discussions and communication. By making comprehensive field notes researchers are able to maintain maximum control over the situation.

\section{Recording of the data}

The interviews were recorded on a video camera (with the written consent of the participants). Videotapes were transcribed verbatim by the main researcher after the interviews. Copies of the videotapes were kept in safe storage to ensure confidentiality and historical record. Throughout the process, attention was paid to the rights of the participants (right to privacy, right to anonymity, right to fair treatment and right to protection from discomfort and harm) (Burns \& Grove, 1997). Immediately after each interview, field notes regarding the interview were recorded in writing by the main researcher. The field notes included the main researcher's account of events taking place, actual discussions and communication as well as any important factors that might have influenced the participants' responses. 
TABLE 2

Reasons for high positive interaction

\begin{tabular}{ll}
\hline Theme & Sub-theme \\
\hline Personal characteristics & Positive personality characteristics \\
& Being focussed \\
Family characteristics & \\
Prioritising family activities \\
Clarifying expectations between family \\
members \\
Family understanding and support
\end{tabular}

Description

Having a positive personality and positive outlook on life; actively focussing on the positive aspects of each situation

Learning from others and implementing their suggestions to improve work-life interaction

Embracing change; being open to change and challenges and seeing opportunity in every situation

Setting and following personal and business goals; setting targets and timeframes to achieve goals

Planning; prioritising; organising; having task lists; delegating in order to focus

Making a conscious decision to balance work and home; adhering to the decision through discipline; developing plans and actions to execute the decision

Positioning family as a first priority; prioritising time with family above anything else; making decisions in favour of family activities; having a value system built on family activities

Being upfront and honest with family members about expectations; clarifying schedules and commitments for the week upfront with family to guarantee realistic expectations

Family understands and supports the organisational culture; family developed with the organisation and understands the culture and requirements; family is comfortable with organisational requirements, hours, pressure and demands

Having a supportive family; family understands organisational demands; family supports and motivates a career in the organisation the ability to handle complex problems in the job due to competence and experience in the job

A meaningful job

Having a meaningful and enjoyable job; having a job that adds value to other's lives

Flexibility and autonomy

Having flexible working hours; being able to work from home; being able to work adjusted hours; job hours and location adapted to personal needs (e.g. being able to pick children up from school; being able to attend sports and recreational activities in the afternoons; provision for peak-time traffic taken into consideration)

\section{Data analyses}

The videotapes of all interviews where transcribed verbatim by the main researcher and the technique of content analysis was used to examine the interview data. This process was applied in order to determine the main themes regarding the use of strategies associated with the high/low interaction group. A number of steps were followed during the course of conducting the content analysis, including analysing and universalising the content, defining and categorising the content, determining themes and sub-themes, categorising the participants' answers into themes and converting the participants' answers and terminology into scientific constructs (Giorgi, 1985). The words, sentences and stories in the transcribed interviews were universalised and categorised into groups. The number of references to a group was noted in a table, differentiating between participants from the high and low positive interaction group respectively. If a key word, sentence or story did not fit into any of the groupings, a new group was added to the table. Thereafter, the table of analysis was studied and themes as well as sub-themes were formed from the identified groups. These themes and sub-themes were named and converted into scientific constructs.

\section{Strategies employed to ensure quality data}

According to Silverman (1993), reliability and consistency of data in qualitative studies can be ensured by using trained interviewers, advanced interview techniques as well as two or more coders to check the reliability of codes allocated to the responses to the questions. In this study, the interviewer was trained in interviewing techniques prior to conducting the interviews. In addition, a co-coder worked independently to code responses and group concepts into themes. The interpretations of the main researcher and the co-coder (second author) were compared and combined in order to ensure reliability of coding.

Validity refers to the trustworthiness and credibility of the research findings and is defined by Mishler (1990) as the degree to which one can rely on the concepts, methods and inferences of a study as the basis for creating one's own theories and as support of empirical research. The principles of credibility (checking the truth value of the findings) and transferability (ensuring applicability of the findings), as defined by Mishler (1990), were adhered to throughout the study. This was ensured by using methods of clarifying and restating the participants' responses, using a standardised approach for each interview, analysing and interpreting field notes, independent coding and the storing of transcripts and original videotapes, as suggested by Winter (2000).

The trustworthiness of the content analysis was promoted by the coding conducted by the researchers involved. Validity was promoted by spending sufficient time with the participants to establish rapport. Socially desirable responses were minimised by using dialogue techniques. Rephrasing and repetition of questions were used to enhance the credibility of information.

\section{Reporting}

The outcome of the interviews is reported in the findings section of this article. Broad themes consisting of various sub-themes and key words were identified. Each broad theme is discussed from the participants' point of view. For illustrative purposes, selected quotes that verbalised the experiences of participants were used. These quotes are representative of the participants' 
TABLE 3

Reasons for low positive interaction

\begin{tabular}{lll}
\hline Theme & Sub-theme & Description \\
\hline Characteristics inherent to the job & Time-related aspects & $\begin{array}{l}\text { Working long hours (including weekends and public holidays); working excessive amounts } \\
\text { of overtime }\end{array}$
\end{tabular}

Strain-related aspects

Physical restrictions

Characteristics inherent to the organisation Unsupportive organisational culture

Unsupportive manager

Stressful emotions

Lack of support

Personal sacrifices
Not being able to adapt working hours to suit individual needs (cannot pick children up from school; provision for peak-time traffic not taken into consideration); not having the opportunity to work flexi-hours or to work from a flexible location (e.g. home, an office closer to home)

Having busy or peak times during the year/month/week when long hours are required

Working with incompetent co-workers and/or subordinates; working with a relatively new team; working with colleagues with less experience

Working under stress and pressure due to job demands

Crisis management of several aspects of the job; having a significant number of urgent tasks with tight deadlines; dealing with urgent queries and requests from colleagues

Having a challenging job and work environment; having a job that challenges current abilities and skills; having a job that is very complex

Having a job that can only be done at the office; not being able to work remotely due to technology, systems, network access and/or work processes

Specialised expertise (e.g. not having someone to stand in when on leave); having knowledge of and controlling processes that cannot continue when absent

Unsupportive organisational culture; organisational culture does not encourage working from home or working flexi-hours; organisational policies supports flexible work arrangements, but are not practically implemented

Limited career possibilities; working hard and long hours without any opportunity to be promoted

Lack of support to complete the job in terms of process, management and/or financia support

Pressure from manager; lack of support; pressure regarding deadlines and quality; unrealistic expectations resulting in stress

Not getting recognition for a job well done

Experiencing regret as a result of spending less time with the family; feeling disappointed for having to cancel family commitments due to work priorities

Having an urgent need to spend more time with family (specifically partner and/or children)

Having insecure feelings in the marriage; experiencing marital conflict due to work commitments

Feeling guilty and stressed about not spending time at home; feeling guilty about having work as first priority

Having no external family and friends to help manage the work-home interface

Spending valuable time in traffic (being unproductive)

Sacrificing health and fitness due to work commitments; not being able to participate in recreational activities due to working hours feelings and experiences and are by no means exhaustive. The exact words of the participants were used where possible, but in some instances the quotes were adapted to more formal English to ensure ease of reading and proper sentence construction.

\section{FINDINGS}

The findings of the exploratory qualitative phase of the study were organised into two sections, each with various themes and sub-themes, namely, (1) reasons for high or low positive interaction and (2) strategies for positive interaction. Each theme with its relevant sub-themes is discussed. The respective tables show the themes, sub-themes and a short description for each theme.

\section{Section 1: Reasons for high and low positive interaction}

From the first question asked during the interviews 'Why do you think you experience this high/low interaction between your work and home life'), certain recurring themes were extracted. Reasons were categorised and grouped together to form themes and sub-themes. Table 2 indicates the reasons for experiencing high positive interaction and Table 3 specifies the reasons for experiencing low positive interaction.

Participants in the high positive interaction group could easily identify reasons for experiencing this type of interaction. Personal aspects, family characteristics, characteristics inherent to the job and characteristics inherent to the organisation were identified as themes. Participants in this group mentioned personal aspects such as having a positive personality and positive outlook on life, embracing change, as well as being open to learn from others (e.g. mentors) as salient reasons for experiencing high positive interaction between work and home. Participants made statements such as the following to motivate these reasons:

Personally, I have high energy. I always see the positive side even during difficult times.

The first reason for me experiencing this positive interaction is the fact that I embrace change. There is one constant in life and that is change. 
The more feedback I get, the better I get at it. Communicating with others and learning from others is key for me because life is too short to make all the mistakes myself. Fortunately I have many older friends who coach and mentor me. I sort of look up to them.

(Participants)

Another personal aspect contributing to high positive interaction included being focused through planning, prioritising, organising, having task lists and delegating as well as setting and following personal and business goals and timeframes. Participants mentioned the following:

I plan and assign a certain amount of hours to a task.

I work with to-do lists. I plan my to-do list for work on a daily basis. I also have a personal to-do list and when I remember something I prioritise it immediately.

You have to be very organised here and through being organised you are efficient.

(Participants)

Some participants mentioned how making a conscious decision to balance work and home assists them in facilitating positive interaction. Quotes that support this notion are the following:

We had to make a conscious decision to change the dynamic because we were heading in the wrong direction.

My focus changed dramatically after I suffered some back problems. I realised that my health and my personal life are important. More important than work.

(Participants)

Family characteristics constituted another recurring theme that was identified and comprised of prioritising family activities above work activities, clarifying expectations and having a supportive and understanding family. Participants in this group were insistent about having strong family values. For example, one of the participants mentioned, 'I started with the right basis in my family values', while another said,

My family is very close and I like to engage with people. Every night, no matter when it is and even if I come home late, the table is set and we eat together as a family.

(Participant)

Being upfront and honest was mentioned frequently, with one participant describing the process very practically:

For example, I got them together, the kids and the girlfriend. I asked them to sit down and I said right, this is what I am going to do. This is how long it is going to take. These are the dates, the weekends. I need you to understand and accept it and work with me on this. I need to do this because the future after this will be a lot brighter, hopefully. So work with me.

(Participant)

Most of the participants in the high positive interaction group felt that they have a supportive and understanding family. One participant mentioned that his family 'grew up' with the company and that they are grateful for the organisational support throughout the years. Due to this reason, they understand when he needs to work long hours because they fundamentally understand the nature of the business and are proud of the organisation.

The third recurring theme was having supportive job characteristics. These included flexible working hours, being able to work from home, having a meaningful and enjoyable job, being competent and familiar with the job and having enough experience to be comfortable in the job. This theme is supported by various personal declarations, including the following:

Just remember, I've been in my job for quite some time.

Now that [my team] is familiar with my standard and know which balls to chase, the pressure has slowed down and we have come to accept the organisational changes and the pressure that goes with it.

(Participants)
It became clear during the interviews that employees with high positive interaction recognised the role of their managers in facilitating this positive interaction. Employees with high positive interaction frequently mentioned support from their managers as one of the reasons for their positive experience ('My dad was in hospital for a while. Again, the flexible working environment [...] helped me. Going to the hospital three times a day for about a month, work just fitted in around that. My manager is very understanding. He came to the hospital a few times, he was very supportive'). Participants explained that management support can assume many different guises. Support in terms of understanding, measuring outputs rather than inputs and having empathy are all valuable in facilitating positive interaction between work and home.

The group of participants who experienced low positive interaction between work and home was asked to give their opinion as to why they experience low positive interaction. Their experiences were grouped together and three main themes were identified as reasons for low positive interaction. These included characteristics of the job, characteristics of the organisation and personal aspects, as depicted in Table 3.

Job characteristics that contributed to low positive interaction comprised mainly time-related and strain-related issues and physical restrictions. The participants typically mentioned long hours, working overtime, not having flexi-time and having busy times in the month to be the most detrimental to positive interaction between home and work. Some of their comments include the following:

I think I work too much; Month-end is always a busy time for me and then my family comes second. I also work over public holidays and weekends - the times that my family needs me most I was just wearing myself out with these long hours, coming to work with less and less energy.

(Particpants)

Strain-related aspects related to working with a new, inexperienced or incompetent team, working with high complexity and having many urgent deadlines. Some of the comments from the interviews supporting this theme are the following:

These urgent deadlines are killing me. If only we had a week or two to complete something, but everything in this business is urgent I still have to train and develop my team. That takes a lot of my time.

Physical restrictions refer to being the only person who can do the job, having to be at the office to complete the job and not being able to work flexi-time. This sub-theme is supported by statements such as,

I am the only person in our team with the expertise to make decisions about technical assistance. If I am not at the office and a query comes through, there is nobody who can analyse and make a decision. It means I cannot work flexi-time. I have to be in the office eight to five.

(Partcipant)

Organisational characteristics proved to be an important contributor to low positive interaction and included an unsupportive organisational culture and lack of support from management. Participants repeatedly mentioned that the organisational culture does not support a work-life balance and does not reward and reinforce behaviours that would lead to better work-life balance. One of the participants specifically mentioned the following:

There is no support. They are saying to the employees if you work all night we will reward you. But you have to go out and ensure you have work-life balance. The two contradict each other. You need to tell people, you know what: Showing effective time management, getting the job done in the required time[...] effective time management, job completion, by due date, that is the stuff we want to reward. Not the guy who worked all weekend. (Participant) 
Other participants supported this view by also mentioning the following: '[The organisation] probably has the highest divorce rate in South Africa' and 'I didn't realise that there is such a dissonance in our value system'. These statements clearly show the discontent that employees experience in a culture that is not perceived as supportive of a positive work-life balance, flexible work arrangements and respect for personal time. Participants with low positive interaction referred to the organisational culture as being detrimental to their home lives.

Lastly, participants in the low interaction group mentioned certain personal aspects as reasons for experiencing low interaction. Having work as first priority, having to cancel family commitments, insecurities about their marital relationships, lack of support, spending time in traffic being unproductive and sacrificing health and fitness due to work commitments were all factors that contributed to low positive experiences between work and home. Some of their comments on this theme include the following:

Work comes first, as you know.

All day work, all night work. I believe that possibly, 50\% of that was the reason why I got divorced.

Having gone through what we've gone through, call it a couple's dilemma.

I spend a lot of time in the traffic. Unproductive time where I could have done a lot of work.

I'm experiencing health problems due to this lifestyle and I cannot keep this up.

(Participants)

\section{Section 4: Strategies for positive interaction}

After arriving at a more comprehensive understanding of reasons why participants (lack) experience of positive interaction, the interviews were also specifically aimed at arriving at insights regarding possible strategies for positive interaction between home and work. The second question that the participants were invited to answer (What strategies do you use to manage the interaction between work and home life?) provided the data necessary for determining strategies associated with high and low positive interaction between work and home. The themes with their sub-themes and participant responses can be seen in Table 4 and Table 5 .

The analysis of the interviews, as presented in Table 4, led to the identification of 10 themes related to strategies used by participants with high positive interaction between work and home. Each of these strategies is briefly explained and examples are also given.

\section{Integrating work and personal activities}

Integrating work and personal activities was a strategy mentioned by most of the participants in the high positive interaction group. Participants mentioned a wide variety of tasks that they use to integrate their work and personal activities. These activities ranged from actively building work into personal activities, working from home, working over weekends, involving family in work activities and the organisational culture, sharing work stories with family members, interacting with colleagues after hours, befriending colleagues and celebrating organisational success with the family. It was constantly mentioned that the integration of work and personal life facilitates positive interaction between work and home.

Participants commented that working from home in the week during office hours as well as over the weekend is a successful strategy for positive interaction. They stated the following:

I often take care of personal tasks during office hours and then work at home over weekends. Let's say about two hours or even more on a Saturday and a Sunday. It makes me feel good to know that I have that flexibility.

It is not a problem for me to sort things out over weekends on
Saturday mornings over the phone from home. It is part of my life and I accept it and do it with a smile. At least I can solve these problems from home and I don't have to sit in the office

I don't feel guilty if I have to go home while a contractor is fixing something because I can log on to the network with my laptop and work from home.

(Participants)

One participant specifically mentioned how she appreciated her family's interest in her work by commenting,

What is nice about my family is that they want to know about my day. When I get home we will have a discussion about what happened at work.

(Participant)

Another participant, a father of two young children, explained how he tries to excite his children about his work and the company:

I try to make it exciting for them. When we pass a truck with our products I will tell them to look and wave at the driver. I would explain to them what I do to get those products to consumers. It makes them proud that their dad is part of such a successful company.

(Participant)

Social interaction with colleagues was mentioned in different formats. This was deduced from statements such as

I integrate work relationships and personal relationships by spending time with colleagues after hours, which helps me a lot. It is good to offload to people who understand the culture and environment.

I get to know my colleagues' families and friends. I care about their personal lives and their families and they are positive and supportive towards me as a result.

(Participants)

Lastly, participants indicated that they share the rewards from their hard work with their families and friends. One participant mentioned this as his most important strategy:

I do my work and I do it well and when I get rewarded, I take it home! I always bring my happiness, reward and recognition home to share it with the people who supported me through it all.

\section{Managing time at work and personal life}

This theme was deduced from statements from participants related to time management and planning. Firstly, participants mentioned working flexi-time and adjusted hours by stating, 'I work from 6:00 to 15:00 to miss the traffic. I enjoy this flexi-time because it gives me more time at home and more productive hours at work'. Participants also mentioned using activities that assist them in scheduling time specifically for family and personal activities with statements such as

I plan my home activities and put these plans into action before I go to work. For example, I communicate to my daughter and her babysitter what my programme for the week entails and she tells me what activities she needs to attend. We then buy whatever is needed for the week, put transport money aside and get all her homework done. This way I know that when I go to the office and have meetings, I don't have to stress about her.

I manage my time and ensure that there is enough time allocated to family and work.

At least one day in a work week, I leave early and do my shopping and administrative tasks so I don't have to use my Saturdays and Sundays to do this.

(Participants)

Planning, prioritising, organising, keeping task lists and applying discipline in order to execute these plans also contributed to the time-management theme. This can be proved by quotations from various participants: 'I manage my time with my Outlook calendar every day' ; 'I use to-do lists. I've got a personal to-do list and a work to-do list. I cross it out once the task is completed'; 'I don't say yes to all meetings. I prioritise 
and decide what is more important' and 'You have to plan your time. Have time to play, time to work, time with family'.

\section{Defining values}

Recurring activities regarding family values emerged from the interviews. Participants discussed the ways in which they communicate their work and home objectives, how they set goals with their families and how they prioritise family activities. They mentioned that honesty and integrity are essential values without which positive interaction between home and work would not be possible. These activities emerged clearly in the interviews when participants mentioned the following:

I sat down with my wife and kids and explained to them what type of work I have and what the demands are on me and our family time.

My family and friends understand the nature of my work and they support me. They know that I won't be at all the birthday parties and social gatherings but they understand and they accept it because I clarified it upfront and I share and celebrate the rewards of my hard work with them.

I have been brought up with strong family values and I communicate these values to my family and colleagues on an ongoing basis.

(Particpants)

These activities were grouped together to form a strategy called 'Defining values', which refers to the act of being open and honest with family regarding commitments and priorities.

\section{Recreation and relaxation}

Most of the participants in the high positive interaction group mentioned that they participate in relaxation and recreation of some sort. Some of the participants' comments in support of this strategy are on exercising and physical activity:

During the work week it gets very hectic so you need to have something that you can look forward to outside work. Action netball for me is something I look forward to as relaxation. I think you need some kind of physical activity that you can do to just relieve stress.

I need to get some kind of physical activity, so I try to go to the gym when I can.

Playing sports helps me manage my job and personal life. Through sport I learn characteristics of hard work and teamwork.

(Participants)

Other participants viewed relaxation from a different perspective and discussed holidays and social activities as their way of relaxing and recharging:

I would go to movies, clubbing or dinner every now and then with my friends to relax. By the time I come back to work I am motivated and I feel refreshed and ready for the week.

I actively make time to spend holidays with my family I go on holiday at least once a year with my wife. We go alone and leave the kids at my parents.

(Participants)

\section{Religion}

Some of the participants mentioned that they use religion to inspire and motivate themselves. Religion as a strategy for positive interaction between work and home was brought to light in an insightful manner by one of the participants, who said, 'I am very religious and trust God to help me overcome obstacles. I know that in God everything is possible for me'. Another participant commented, 'I go to church to find inspiration and to gather my strengths for the week'. The participants who mentioned religion as strategy were very confident that without religion, they would not be able to experience such a positive interaction ('I can't do this on my own. Without my faith, my work-life balance would be a mess').

\section{Social support}

Social support emerged as a strategy that consists of various activities, including getting guidance from coaches and mentors, getting feedback from significant others and having a supportive social structure in terms of family members as well as work colleagues. Firstly, participants in the high positive interaction group mentioned coaching and mentoring as well as support and feedback from significant others frequently. One participant explained the effects hereof with a striking story:

Learning from others is very important to me. I have older friends who coach and mentor me continuously. I look up to them and I learn from their stories. I've got a family friend who got divorced at some stage. He learnt from his first marriage and is now transferring that knowledge onto me.

(Participant)

Secondly, support from family members seemed to be an important strategy - this was clarified by a young man participating in the study: 'My family and friends believe in my dreams. They know what I want to achieve and they support me in it'. Thirdly, participants also mentioned support from colleagues:

My manager is definitely supportive. He does not mind if we work from home and he is incredibly supportive of work-life balance. I would say that building a positive relationship with him is one of my most efficient strategies for managing the interaction between work and home.

I've got supportive co-workers who understand the situation and stand in for me when I have a crisis at home.

(Participants)

\section{Positivity}

A fascinating strategy is managing the work-home interface purely by being positive. Having a positive personality and mindset and being open to challenges and change were mentioned frequently by participants in the high positive interaction group. These participants felt that their positive outlook on life helps them to cope with the difficult interdependencies between work and home. They referred to positivity by means of various different statements, including the following:

It is all about a mindset and I believe that even though work and home responsibilities are both stressful I can balance the two.

For me, seeing the positive and embracing change is part of my personal development which I focus on all the time. I try to enhance my skills and I read a lot about these topics.

(Participants)

One participant summarised this quality light-heartedly by saying,

I think it is all due to my blood type. I am a B+, which indicates that I always have to 'be positive; I live by that mantra and it is part of my personality. There is no challenge too big for me, it is just in my blood to overcome challenges with my positive attitude.

(Participant)

\section{Delegation and training to alleviate job load}

Some of the participants mentioned that they train their subordinates in order for them to assume some of their own or some of the team's responsibilities ('I decided to train one of my subordinates to do time errors. This saves me time because while he is busy correcting the time errors, I can focus on other more important tasks'). Participants also mentioned coaching as a development tool for their subordinates, which is used in order for them to save time ('I train and coach my subordinates to think for themselves and solve their own problems. I will assist them in their thinking, but I cannot solve their problems for them and add to my load'). Once subordinates are competent, these participants then feel more comfortable to delegate some of their responsibilities ('I started delegating some of my work to team members knowing that the job will 
TABLE 5

Strategies used by participants with low positive interaction

\begin{tabular}{ll}
\hline Theme & Description \\
\hline Passivity & $\begin{array}{l}\text { Not having or implementing any tangible strategies; not engaging in active strategies or actions to improve the interaction } \\
\text { between work and home life; not thinking about the pressure and avoiding thoughts of insufficient balance; ignoring the } \\
\text { conflict between work and home }\end{array}$
\end{tabular}

Avoid dealing with the problem

Considering leaving the company to improve interaction between work and home; looking for another job with better circumstances and support; thinking about resigning and starting an own business

Separation by keeping work and home life apart Not noking calls after hours; switching off the cell phone and blackberry after hours; not engaging in telephonic conversation after hours

Not working from home; leaving the laptop at the office; not switching on the laptop when at home; trying not to engage in conversation with colleagues after hours

Not working or talking about work when with the family; not sharing information and stories about work with family

Working longer hours to complete tasks at work in order to relax at home; rather doing work at the office and staying there longer than working from home

get done. Not necessarily the way I would have done it, but it will get done some way or the other'). For them, this strategy is valuable in terms of the reduction of workload and in terms of being more efficient at work.

\section{Changing perspectives}

In some instances, participants mentioned that they had tried various strategies but that none of these strategies were effective until they made a fundamental change to the way they were managing and how they perceived the interaction between work and home. Changing goals and priorities in terms of work-home interaction was also beneficial. One male participant shared his story:

I've always been an excellent performer, winning all the awards, taking on all the extra projects, meeting clients for functions in the evenings. I did everything it took to prove that I am the best in my field and I consistently applied time-management strategies to try to balance home and work. Then, a tragedy happened in my personal life and I wasn't even home to support my wife. I realised that my strategies did not support a healthy, balanced lifestyle and I was shattered. I realised that I had to make a decision to change my lifestyle. When a promotion was offered to me soon thereafter, I decided not to take it and to move out of the department in order to live a more balanced life. This decision was a hard one to make and I had to sacrifice many of my career goals. But in terms of quality of life, I couldn't have followed a better strategy.

(Participant)

\section{Challenging organisational perception of success}

The final strategy used by participants with a high positive interaction between work and home is fighting the reputation that exists in the company that working long hours and giving up family time indicates that one is a hard worker and a successful employee. Many of the participants mentioned that this organisational belief has a harmful effect on their family lives and that they are trying to show their colleagues and managers that the same quality of work can get done in less time if one is an efficient worker. One participant specifically mentioned the following:

I always had a reputation that I am a performer, that I will be able to do my job and extra projects. I try to fight that reputation and say: Yes, I can do all of this, but it is killing my family life. I can perform and I can do extra work, but I choose not to. I choose to do my job to the best of my ability and spend my free time with my family instead of with extra projects.

(Participant)

Participants in this study also mentioned that they try to set an example to their subordinates in terms of living a healthy, balanced life:

I motivate work-life balance in my team by being the example. I leave the office at five and tell my team that it is now time for my child's soccer match. They see my example and by following my lead, they are part of the revolution that is fighting this contagious culture.

(Participants)
Participants in the low positive interaction group used different strategies from the ones discussed above to manage the interaction between work and home. The strategies mentioned by these participants are outlined in Table 5 and discussed in more detail thereafter.

As can be seen in Table 5, three broad themes emerged from the responses of participants with low positive interaction between work and home. The first theme was passivity, which participants referred to by using expressions such as

I don't believe I have an actual strategy. At the end of the day you must just try to be happy and move on I cannot tell you one single thing that I do to try and facilitate positive interaction between work and home. I just live from day to day.

(Participants)

The second theme was avoidance, expressed by the participants through statements such as 'I am considering leaving the company to achieve better balance' and 'To be honest with you, my CV is on career junction. As soon as I get another job I am leaving this place'.

The third theme, separating work and home by trying to keep these two domains apart, was mentioned frequently by both participants with high positive interaction and participants with low positive interaction. However, this was the second most prevalent strategy mentioned by the low positive interaction group and it was mentioned significantly more frequently by participants from this group. Separation included tactics such as not taking calls after hours ("This may sound radical, but I leave my phone in the car when I get home. I just don't answer calls after hours' and 'I switch my phone off over weekends. If you create a precedent by taking work calls over weekends, you will always be expected to answer over weekends'), not working from home ('I manage the interaction between work and home by not taking any work home' and 'I never work from home. I feel it is unfair towards my family'), not sharing information and stories about work with family (' $\mathrm{I}$ don't burden my wife with my stories from work. She doesn't want to hear it and she doesn't understand it' and 'My husband and I have got an agreement not to talk about work at home') and working longer hours in order to complete work at the office and consequently not having to work from home ('I don't take work home. I'd rather work longer hours in order to finish my tasks for the day, but when I get home, it is home time' and 'I try to get my work done at the office. Sometimes I leave quite late on a Friday, about 19:00 or 20:00, but I know that my work is completed').

\section{DISCUSSION}

The objectives of this research were to determine reasons why employees experience high or low positive work-home interaction and to determine strategies that employees with high and low positive interaction use. Firstly, individuals with high and low positive interaction between work and home were 
identified using quantitative surveys. Thereafter, exploratory qualitative interviews were conducted with a view to finding answers to the research questions.

General conclusions were reached in support of existing literature, but new themes also emerged that were previously unexplored. Unique trends and differences between groups are discussed below, together with supporting literature to illustrate the experience of the participants with regard to positive interaction between the domains of work and home.

\section{Reasons for high or low positive interaction between work and home}

It was clear from the results that participants from different groupshaddifferentreasonsforexperiencinghighorlow positive interaction. The participants from the high group experienced that characteristics inherent to their jobs were conducive to a work-life balance, while the low group experienced exactly the opposite and stated that the characteristics of their jobs were detrimental to their home lives. They also mentioned non-supportive organisational characteristics such as an unsupportive manager and organisational culture as opposed to supportive managers, mentors and coaches highlighted by members of the positive group. These findings support previous research findings (Dex \& Bond, 2005; Grzywacz \& Marks, 2000). Family characteristics were mentioned by the high group with reference to prioritising family activities, clarifying expectations and having family support. These types of support were visibly absent among members of the low group and can thus be identified as important contributors to positive interaction between work and home. This finding concurs with previous research conducted by Carlson and Perrewe (1999) as well as Demerouti, Geurts and Kompier (2004). The surfacing of these reasons prompted further questions regarding home and work characteristics, which were explored in the interviews.

An important conclusion of this study, which also supports the literature, is that positive interaction is not achieved through one main factor in an individual's life, but by a combination of causes in a given environment (Dex \& Bond, 2005; Grzywacz \& Marks, 2000). Positive personality characteristics (Grzywacz \& Marks, 2000), prioritising family activities (Carlson \& Perrewe, 1999; Parasurman \& Simmers, 2001), family support (Parasuraman, Purohit, Godshalk \& Beutell, 1996), having a meaningful job (Clark, 2002; Wallace, 1997), flexibly and autonomy (Grzywacz \& Marks, 2000; Mostert \& Oosthuizen, 2006; Parasurman \& Simmers, 2001) and support and mentoring (Grzywacz \& Marks, 2000) were all found to be antecedents of high positive interaction by previous researchers. Interestingly, being focused, clarifying expectations and job experience and skills are rarely mentioned as reasons for high positive interaction in the literature.

Reasons for low positive interaction identified in this study are also supported by various theories and research findings. It has been found that time-related and strain-related issues and physical restrictions of the job lead to lower positive interaction (Carlson \& Kacmar, 2000). Other reasons include an unsupportive organisational culture, an unsupportive manager, stressful emotions and lack of support, all of which are supported by previous research (Carlson \& Perrewe, 1999; Clark, 2002; Eby et al., 2005; Geurts \& Dikkers, 2002; Wallace, 1997).

The themes linked to positive interaction identified in this study, consisting of the reasons mentioned above, are in congruence with various previous studies. Geurts and Dikkers (2002) mention that there are various antecedents of (negative and positive) interaction between work and non-work and that these can be classified into job-related factors, family-related factors, personality characteristics and attitudes. This classification closely resembles the themes identified in this study - which outlined job characteristics, organisational characteristics, personal aspects and family characteristics as reasons for high and low positive interaction. Eby et al. (2005) concur and report that work characteristics, family characteristics and personal characteristics are the main predictors of high positive interaction.

\section{Strategies}

Successful as well as unsuccessful strategies for positive interaction between work and home were identified and comparisons were drawn with previous research findings. Four of the strategies identified in this study concurred with previous research findings. They were managing time (Duxbury, 2004; Duxbury \& Higgins, 2003), religion (Beehr et al., 1995), social support, (Brough et al., 2005; Carlson \& Perrewe, 1999; Duxbury, 2004) and positivity (Duxbury, 2004; Kirchmeyer \& Cohen, 1999). In addition, six new strategies were identified, including integrating work and personal activities, defining values, relaxation, delegation and training to alleviate job load, making a conscious decision or change in order to remove oneself from the situation, and challenging organisational perceptions of success. The unsuccessful strategies identified in this study were passivity, avoidance and separation. The strategies passivity and avoidance were in congruence with previous research on unsuccessful strategies for positive interaction (Brink \& De la Rey, 2001; Stoner et al., 2005), while separation was identified as an additional unsuccessful strategy.

Successful themes mentioned most frequently include time management (identified by $94 \%$ of the high positive interaction participants), integration (identified by $71 \%$ of the high positive interaction participants) and defining values (identified by $60 \%$ of the high positive interaction participants). It can be concluded that these three themes are the most widely used effective strategies for positive interaction between work and home.

Separation proved to be a complex theme, being the only strategy mentioned by significant numbers of participants from both the low positive interaction group $(60 \%)$ and the high positive interaction group $(60 \%)$. However, this was also the strategy identified most frequently by participants from the low positive interaction group. It seems as though separation can be either an effective or an ineffective strategy, depending on the work and home characteristics of the participants using this strategy. The reasons for these differences should be further explored in future studies in order to attain clarity with regard to the success of separation as a strategy for positive interaction between work and home.

The above-mentioned findings can be summarised in order to identify the most effective organisational and personal strategies that would facilitate positive interaction between work and home. In order to address the most prevalent reasons for low positive interaction, the organisation can focus on shifting the current unsupportive organisational culture towards a culture of engagement, supportive leadership and autonomous work, in addition to flexible work arrangements. More key strategies may be to create a pipeline of competent teams in order to stand in for managerial employees when they go on leave and to ensure social support systems within the organisation.

Individuals can strive towards a healthy lifestyle, focussing on sport, relaxation, recreational activities and creating a relaxed home environment, in order to minimise antecedents for low positive interaction. Strategies that would prove to be beneficial to individuals are time management, integrating the work and the home domains, defining values to live by and seeking social support. In addition, other strategies can be applied with a possibly lesser effect, such as practising religion, developing the 
team in order to alleviate job load and, lastly, taking bold action by changing the circumstances preventing the individual from experiencing positive interaction.

\section{Limitations}

This study posed several limitations that should be considered when applying and generalising the results. The first limitation was the conceptualisation of the terms 'work-home interaction' as opposed to 'work-life balance', which the participants are familiar with. Participants might not have been able to identify the correlation between these two constructs. However, this limitation was managed by clarifying the definition of the constructs upfront in the interviews. The second limitation is that the questionnaire used in this study refers to work and home only and does not include other possible roles of personal life (hobbies, studies, spirituality, etc.) that could possibly influence the employee's perspective of interaction between the two broader domains under investigation. Recommendations for future research in this regard would be to use a questionnaire that incorporates a wider variety of roles in an individual's personal life.

The third limitation relates to the exclusion of gender differences. Previous research results indicate that men and women experience the interaction between work and home significantly differently, and these differences were not investigated in this study. Also, the number of children and their ages was not included in this study. These factors might contribute to the levels of positive interaction between work and home. Other factors that could influence the experience of positive interaction between work and home include marital status, marital status combined with the number and ages of children and managerial level.

The fourth limitation is that the possibility always exists that some of the participants may have been concerned about the confidentiality of the interview and the use of video recorders. This might have influenced their answers and the outcome of the results. In order to minimise the effect of the fear of being recorded, the interviewer briefed the participants about the use of the video camera and explained the reason behind record keeping. The interviewer attempted in all instances to set the participants at ease and she confirmed that their identity would remain anonymous. The fifth limitation of this study is that it considered only one organisation in the beverage-manufacturing and distribution industry, and recommendations for future research would include extending this type of study to include other organisations in order to obtain a more comprehensive view of the entire industry.

\section{Recommendations}

The limitations mentioned were managed carefully and did not have a detrimental effect on the results and recommendations emanating from the findings of the study. The implications for individuals, organisations and researchers wishing to conduct further research in this field include the use of a measuring battery that takes into account multiple life roles. Another suggestion for future research is an investigation into the correlation of personality type with strategies and the success thereof. Finally, future researchers are encouraged to control for gender, age, marital status and number and ages of children through quantitative studies wherein the differences among different groups can be statistically determined and reported. Controlling for these variables when measuring positive interaction between work and home can assist in understanding how different individuals experience this interaction and how reasons and strategies differ among these groups.

The findings and recommendations can be used by the organisation studied in order to create an organisational culture that is supportive of positive interaction between work and home using the identified strategies. To conclude, the value of these recommendations for future research lies in their ability to provide guidelines for the design of effective strategies aimed at improving the integration of work and personal life. This organisational strategy can be expected to have a positive effect on people's functioning within and outside the workplace, which, in turn, would be beneficial to employees, their families, organisations and society at large (Geurts \& Dikkers, 2002).

\section{REFERENCES}

Bakker, A.B., \& Geurts, S.A.E. (2004). Toward a dual-process model of work-home interference. Work and Occupations, August, 345-366.

Beehr, T.A., Johnson, L.B., Nieva, R., \& Hurrell, J.J. (1995). Occupational stress: Coping of police and their spouses. Journal of Organizational Behavior, 16, 3-28.

Beutell, N.J., \& Greenhaus, J.H. (1983). Integration of home and non-home roles: Women's conflict and coping behavior. Journal of Applied Psychology, 68, 43-48.

Brink, B., \& De la Rey, C. (2001). Work-family interaction strain: Coping strategies used by successful women in the public, corporate and self-employed sectors of the economy. South African Journal of Psychology, 31(4), 55-61.

Brough, P., O'Driscoll, M., \& Kalliath, T. (2005). The ability of 'family friendly' organizational resources to predict workfamily conflict and job and family satisfaction. Stress and Health, 21(4), 223-234.

Burns, N., \& Grove, S.K. (1997). The practice of nursing research: Conduct, critique and utilization. (3rd edn.). Philadelphia: WB Saunders.

Byron, K. (2005). A meta-analytic review of work-family conflict and its antecedents. Journal of Vocational Behavior, 67, 169-198.

Carlson, D.S., \& Kacmar, K.M. (2000). Work-family conflict in the organization: Do life role values make a difference? Journal of Management, 26, 1031-1054.

Carlson, D.S., \& Perrewe, P.L. (1999). The role of social support in the stressor-strain relationship: An examination of workfamily conflict. Journal of Management, 25(4), 513-540.

Clark, S.C. (2002). Employees' sense of community, sense of control, and work/family conflict in Native American organizations. Journal of Vocational Behavior, 61, 92-108.

Demerouti, E., Geurts, S.A.E., \& Kompier, M.A.J. (2004). Positive and negative work-home interaction: Prevalence and correlates. Equal Opportunities International, 23, 6-35.

De Vos, A.S., Strydom, H., Fouche, C.B., \& Delport, C.S.L. (2005). Research at grass roots, for the social sciences and human service professions. Pretoria: Van Schaik.

Dex, S., \& Bond, S. (2005). Measuring work-life balance and its covariates. Work, Employment and Society, 19, 627-637.

Duxbury, L. (2004). Dealing with work-life issues in the workplace: Standing still is not an option. Kingston, Ontario: Industrial Relations Centre.

Duxbury, L., \& Higgins, C. (2003). Work-life conflict in Canada in the new millennium: A status report. Healthy Communities Division, Health Canada. Retrieved November 1, 2006, from http://www.cprn.org

Eby, L.T., Casper, W.J., Lockwood, A., Bordeaux, C., \& Brinley, A. (2005). Work and family research in IO/OB: Content analysis and review of the literature (1980-2002). Journal of Vocational Behaviour, 66, 124-197.

Frone, M.R., Russell, M., \& Cooper, M.L. (1997). Relation of workfamily conflict to health outcomes: A four-year longitudinal study of employed parents. Journal of Occupational and Organizational Psychology, 70, 325-335.

Geurts S.A.E., \& Dikkers, S.E. (2002). The work-nonwork interface: What do we know and where should we go? Paper presented at the European Academy of Management conference, Stockholm, Sweden, Retrieved August 13, 2005, from http:// www.cprn.org/en/doc.cfm?doc $=52$ 
Geurts, S.A.E., Taris, T.W., Kompier, M.A.J., Dikkers, J.S.E., Van Hooff, M.L.M., \& Kinnunen, U.M. (2005). Workhome interaction from a work psychological perspective: Development and validation of the SWING. Work $\mathcal{E}$ Stress, 19, 319-339.

Giorgi, A. (1985). Sketch of a psychological phenomenological method. In A. Giorgi (Ed.), Phenomenology and psychological research (pp. 8-22). Pittsburgh: Duquesne University Press.

Greenhaus, J.H., \& Powell, G.N. (2006). When work and family are allies: A theory of work-family enrichment. Academy of Management Review, 31, 72-92.

Grzywacz, J.G., \& Butler, A.B. (2005). The impact of job characteristics on work-to-family facilitation: Testing a theory and distinguishing a construct. Journal of Occupational Health Psychology, 10, 97-109.

Grzywacz, J.G., \& Marks, N.F. (2000). Reconceptualizing the work-family interface: An ecological perspective on the correlates of positive and negative spillover between work and family. Journal of Occupational Health Psychology, 5, 111126.

Guba, E. G., \& Lincoln, Y.S. (1994). Competing paradigms in qualitative research. In N.K. Denzin \& Y.S. Lincoln (Eds.), Handbook of qualitative research (pp. 105-117). London: Sage.

Hakanen, J., Peeters, M.C.W., \& Perhoniemi, R. (submitted). Do job and home resources trigger work-family enrichment processes over time? A cross-lagged panel study. Journal of Occupational and Organizational Psychology: A Special Section for Extending the Boundaries of Psychological Resource Theories in Organizations

Hammer, L.B., Cullen, J.C., Neal, M.B., Sinclain, R.R., \& Shafiro, M.V. (2005). The longitudinal effects of work-family conflict and positive spillover on depressive symptoms among dualearner couples. Journal of Occupational Health Psychology, 10, 138-154.

Haworth, J., \& Lewis, S. (2005). Work, leisure and well-being. British Journal of Guidance \& Counselling, 33, 67-79.

Heraty, N., Morley, M.J., \& Cleveland, J.N. (2008). Complexities and challenges in the work-family interface. Journal of Managerial Psychology, 23(3), 209-214.

Jones, F., Burke, R.J., \& Westman, M. (Eds.). (2006). Work-life balance: A psychological perspective. New York: Psychology Press.

Kirchmeyer, C., \& Cohen, A. (1999). Different strategies for managing the work-non-work interface: A test for unique pathways to work outcomes. Work \& Stress, 13(1), 59-73.

Koekemoer, F.E., \& Mostert, K. (2006). Job characteristics, burnout and negative work-home interference. South African Journal of Industrial Psychology, 32(3), 87-97.

Koekemoer, E., \& Mostert, K. (2010). An exploratory study of the interaction between work and personal life: Experiences of South African employees. SA Journal of Industrial Psychology/ SA Tydskrif vir Bedryfsielkunde, 36(1), Art. \#801, 15 pages. DOI: 10.4102/sajip.v36i1.801

Kvale, S. (1996). Interviews: An introduction to qualitative research interviewing. Thousand Oaks: Sage.

Lewis, S., Rapoport, R., \& Gambles, R. (2003). Reflections on the integration of paid work and the rest of life. Journal of Managerial Psychology, 18, 824-841.

Lincoln, Y., \& Guba, G. (2003). Paradigmatic controversies, contradictions, and emerging confluences. In N. Denzin \& Y. Lincoln (Eds.), The landscape of qualitative research: Theories and issues. (2nd edn., pp. 253-276). Thousand Oaks, CA: Sage.

Lo, S., \& Stone, R. (in press). Work-family conflict and coping strategies adopted by female married professionals in Hong Kong. Paper submitted for publication.

Mishler, E.G. (1990). Validation in inquiry-guided research: The role of exemplars in narrative studies. Harvard Educational Review, 60, 415-442.
Montgomery, A.J., Peeters, M.C.W., Schaufeli, W.B., \& Van Ouden, M. (2003). Work-home interference among newspaper managers: Its relationship with burnout and engagement. Anxiety, Stress, and Coping, 16, 195-211.

Mostert, K. (2006). Work-home interaction as partial mediator between job resources and work engagement. Southern African Business Review, 10(1), 53-74.

Mostert, K. (2009). The balance between work and home: The relationship between work and home demands and ill health of employed females. SA Journal of Industrial Psychology, 35(1), 1-8.

Mostert, K., Cronjé, S., \& Pienaar, J. (2006). Job resources, work engagement and the mediating role of positive work-home interaction of police officers in the North West Province. Acta Criminologica, 19(3), 64-87.

Mostert, K., \& Oosthuizen, B. (2006). Job characteristics and coping strategies associated with negative and positive work-home interference in a nursing environment. South African Journal of Economic and Management Sciences, 9(4), $429-443$.

Mostert, K., Peeters, M.C.W., \& Rost, I. (in press). Work-home interference and the relationship with job characteristics and wellbeing: A South African study among construction workers. Stress and Health.

Oldfield, G., \& Mostert, K. (2007). Job characteristics, ill health and negative work-home interference in the mining industry. South African Journal of Industrial Psychology, 33(2), 68-75.

Parasuraman, S., Purohit, Y.S., Godshalk, V.M., \& Beutell, N.J. (1996). Work and family variables, entrepreneurial career success, and psychological well-being. Journal of Vocational Behavior, 48, 275-300.

Parasurman, S., \& Simmers, C.A. (2001). Type of employment, work-family conflict and well-being: A comparative study. Journal of Organizational Behavior, 22, 551-568.

Pieterse, M., \& Mostert, K. (2005). Measuring the work-home interface: Validation of the Survey Work-Home Interaction Nijmegen (SWING) Instrument. Management Dynamics, 14(2), 2-15.

Rice, J.A. (1995). Mathematical statistics and data analysis. (2nd edn.). Belmont, CA: Duxbury Press.

Seligman, M.E.P., \& Csikszentmihalyi, M. (2000). Positive psychology: An introduction. American Psychologist, 55, 5-14.

Shaughnessy, J.J., Zechmeister, E.B., \& Zechmeister, J.S. (2003). Research methods in psychology. (6th edn.). New York: McGraw-Hill.

Silverman, D. (1993). Interpreting qualitative data: Methods for analysing talk, text and interaction. London: Sage.

Sonnentag, S. (2003). Recovery, work engagement, and proactive behavior: A new look at the interface between nonwork and work. Journal of Applied Psychology, 88, 518528.

SPSS Inc. (2005). SPSS for Windows. Chicago: Author.

Stoner, C.R., Robins, J., \& Russell-Chapin, L. (2005). On the edge: Perceptions and responses to life imbalance. Business Horizons, 48, 337-346.

Wallace, J.E. (1997). It's about time: A study of hours worked and work spillover among law firm lawyers. Journal of Vocational Behavior, 50, 227-248.

Welman, J.C., Kruger, S.J., \& Mitchell, B. (2005). Research methodology. (3rd edn.). Cape Town: Oxford University Press.

Winter, G. (2000). A comparative discussion of the notion of 'validity' in qualitative and quantitative research. The Qualitative Report, 4, 3-4.

Woods, N.F., \& Catanzaro, M. (1988). Nursing research: Theory and practice. St Louis: Mosbey. 